RESEARCH ETHICS

\title{
Subtle ethical dilemmas in geriatric management and clinical research
}

\author{
A J Rosin, Y van Dijk
}

J Med Ethics 2005;31:355-359. doi: 10.1136/jme.2004.008532

Routine management of geriatric problems often raises ethical problems, particularly regarding autonomy of the old person. The carers or children may be unaware of the sensitivity of role reversal in dealing with the financial affairs; the need for a residential carer may compromise the old person's privacy. Attending a day centre confers much benefit, but one must understand the old person's resistance to change in the proposal of a new daily regimen. Similarly his or her autonomy must be the priority in planning for admittance to an old age home, and not the assumption that the family knows best. A common dilemma is the assessment of an old person's competency in decision making, either about management of his affairs, or regarding consent to treatment, or participation in research. Because cognitive capacity is not always identical with competency, meaningful tools have recently been developed in which the emphasis is on the specific situation to be investigated.

See end of article for authors' affiliations

Correspondence to: A J Rosin, Department of Geriatrics, Shaare Zedek Medical Center, Jerusalem, Israel; e-mail: martar@md.huji.ac.il

Received 29 April 2004 Accepted for publication 30 April 2004
$\mathrm{T}$ he altered interactions between the elderly patient and his or her environment may bring about ethical dilemmas in the behavioural patterns resulting from the stress of illness and care giving. Dependency due to physical, emotional, or mental disability in the elderly infirm person is often aggravated by previous and coexisting dysfunction. This has repercussions also on the family who may be responsible for his management, and also burdened with the old person's care, and there is often an urgent need for reinforcement of the social help needed for this situation. Similarly, the vulnerability of elderly persons may present subtle ethical problems in the determination of their competency to agree to collaborate in clinical research in old age. This paper discusses some of these dilemmas in the management of disability and in the practice of clinical research in old people.

Human behaviour is motivated by:

- Inclusion-the feeling and condition of belonging to a family, and to society;

- Control-over oneself and activity, or control of others-the sense of power;

- Affection-recognition and appreciation by others of one's activity and worth, and mutual manifestations of love. ${ }^{1}$
These entities revolve round the psychology of " $\mathrm{I}$ ", the subjective insight of identity, and the "Me", the objective perception of the person by others. The question of personhood and what constitutes a "person" must also be addressed if infirmity and illness become dominant features of old age. In a discussion defining personhood, it was pointed out that the theory of psychological continuity and connectedness would tend to interpret the demented person as having a different identity, because this syndrome is essentially one of disconnection. ${ }^{2}$ The manifestation of the loss of identity is often expressed by the relatives: "This is not the father/mother that I have always known". In this scenario, his dementia causes him virtually to lose his original autonomy. According to Hughes, however, it is important to see the person as one who is "acting and interacting in a cultural historical context in which he is embedded". ${ }^{3}$ This view of the person as a "situated embedded agent" could therefore imply that even if he suffers from dementia he is not automatically severed from his historical roots and, until or unless he reaches a vegetative stage of complete unawareness of his environment, he should be considered as retaining some measure of autonomy.

\section{AUTONOMY}

Autonomy is a person's ability and opportunity to make decisions relating to his/her own wishes. In a democratic society, many independent people are autonomous, but not all people with autonomy are necessarily independent. A wheelchair bound person-for example, can retain the power to order someone to carry out his wishes, and modern communication technology will enable him to implement many of his ideas and plans. The appearance of dependency, however, and its connotation are often (wrongly) interpreted as loss of autonomy, and this can lead to unethical behaviour. A common and important example is the "role reversal" that occurs with an ageing and infirm parent, in which "the child becomes the father of the man" when he assumes the function of a parent. The child does tasks that the old person previously did alone, or that he did when the child was a youngster. But the role is not exactly the same. Whereas a parent is not accountable to a child to tell him everything that he does for him, it is unethical if the child unnecessarily undertakes

Abbreviations: ADAS-cog, Alzheimer's Disease Assessment Scale-cognition; LS, legal standard; MacCATCR, MacArthur Competency Assessment Tool for Clinical Research; MMSE, Mini-Mental State Examination 
the parent's decision making. The expression of the parent's autonomy is that the decision is taken by him and not for him. Added to this fault is the common lack of appreciation by others, including the children, as to how much apparently irrelevant personal possessions matter to the old person. This applies also to the parent's home, which, however unsuitable it may seem to the son or daughter, nevertheless has longlasting ties that constitute the parent's identity with his past. At the same time, it is also unethical for an old person to insist on retaining stores of rubbish to the inconvenience of his environment just because he cannot bring himself to part from it-as exemplified by the syndrome of hoarding. A more flagrant ethical transgression may occur in the handling of the parent's money, and this is one of the forms of abuse of the elderly, especially when the latter has inadequately maintained his cognitive faculties. Dealing with an old or infirm parent's personal affairs is a delicate balance between the child thinking that he knows best what his parent needs, and what the latter really requires or wants.

\section{OLD, DISABLED, AND ALONE}

When an old person lives alone, or with a disabled spouse, there is often an indication for a living-in attendant. The advantage is the removal of some of the burden of care giving from the family, which allows them to devote time to their own needs and interests. The ethical problem here concerns the invasion of the old person's privacy and autonomy. Moreover, the old person may suffer considerable hardship because of a cultural or communication gap between him and the residential carer, and he may also suffer because of a lack of chemistry between himself and the carer. The dilemma is how to strike a balance between the old person's objective needs and his ability to provide for himself on the one hand, and on the other, the family's concern that he will receive the attention that he needs.

\section{ACCOUNTABILITY - TO THE PATIENT OR TO THE FAMILY?}

A common problem in geriatric practice is the question of the physician's accountability-is it to the patient for whom he should be an advocate, or to the family because of the serious problems they present to him in the management of the old person $?^{4}$ Generally speaking, the patient is the priority but the physician would do well to view this dilemma as a "geriatric situation" - that is, the physician should actually deal with the complex environment of the old person and not just with the old person. In addition to a diagnosis of disease, he has to make a situational diagnosis, weighing up the burden on the patient caused by the illness, and how it affects and obtrudes on the family looking after him. Here he has to exercise his moral as well as his medicosocial judgment, which must be based on personal observation of both sides of the problem, and not on a one sided view or hearsay. If he thereby becomes convinced that the damage inflicted on the family outweighs significantly any benefit that the old person derives from their immediate care, and that an alternative solution need not objectively affect him adversely, it would be justified to give priority to the family's needs. We have experienced-for example, a situation in which a well meaning religious daughter took her elderly, fairly able bodied father to live with her large family of husband and children. During the following year, we were witness to the frequent occurrence of grossly unreasonable demands on the part of her father-demands that he was quite capable of meeting himself-at the expense of the needs of the young family. The distress engendered by his presence and lack of sensitivity, together with the threatened break up of the family, eventually drove us to advise the daughter to arrange his placement in residential accommodation.

Such problems focus on the question of how far a family is obligated to respond to the demand by an obstreperous parent for care and attention when disabled in old age. In a discussion on "The anatomy of neglect" Isaacs, et al, defined some of these circumstances precipitating this conflict. "PreOccupation" is a situation in which the family member(s) are afflicted with meaningful and oppressive burdens, such as terminal illness, or chronically sick or infirm children, to which is now added the demand for care by a disabled parent. Dilemma and refusal may occur where despite much devoted care to the parent, the care of the child's family is the first priority. Rejection of the responsibility for directly taking care of an elderly parent might occur when the parent had abandoned or neglected or abused the family in their youth-for example, an elderly chronic alcoholic. ${ }^{5}$ There cannot be a single answer to these dilemmas compounded of varied personalities and coping abilities. Before making a decision about accountability, there must be a thorough appraisal of the clinical and social facts, often involving other disciplines in the social, ethical, and religious fields.

\section{ABUSE}

Abuse may occur overtly or subtly on both sides. The son might not have exhausted all the possibilities that would allow the parent to maintain his independent living, or he might have relegated his duty to another to escape his own involvement. A "difficult" parent can, however, cause a breach in relationships within the child's family, and the parent may have to be forced to agree to supplementary help for his disability. The limits of the ethical responsibility of a child to her parent, and the extent to which she must sacrifice financially, are often not clearly defined by society. In Jewish law-for example, it is laid down that as long as the parent has means and enough to live on, the son need not lay out money himself. If the parent has no means, the son is obliged to give him support, financially and for his daily needs, but not beyond the point that would put the son himself below the poverty line. In the context of caring for a demented parent it is clearly stated that the duty falls on the son, "until God has mercy on [the father's soul]". But if he is unable to cope physically or emotionally with the care, he is obliged to seek a carer who will certainly meet the required needs of the parent. ${ }^{6}$

\section{ENTERING AN INSTITUTION}

The question of institutional care poses many ethical problems. There may be significant disparity between the views of the old person and that of the children, care givers, or authorities charged with the care of the elderly. Often one hears the claim by the latter "that it is for your own good"-a claim that contradicts the old person's autonomy, particularly if he has been minimally, or even not at all, involved in the decision. Common examples of such paternalism occur when the parent is told that it will be more comfortable for him (in the children's view) to live in an institutional setting, or when the parent is told that he cannot manage on his own, or that because the children cannot be with him all the time, it has been decided that he should enter an old people's home. The dilemma here is that there is often right on both sides. A professional evaluation of the situation, usually by a geriatric team, can often help the children to reach a decision that they can feel is legitimate. If clinical reasoning and moral directives point to the desirability of the old person continuing to be in his own home, the solution may be an increase of social support services and support for the family. If, on the other hand, it is recommended that he should be in 
institutional care, the matter should be discussed in detail with the old person, and there should be visits to a number of such institutions, and temporary trial periods in them, so that he may become acclimatised to the idea of going into an old people's home. There is much to be said for the advantages of the health and social support provided by many residential establishments, and indeed some old people gain a new lease of productive life when they go to live in such an institution. The problem remains, however, of the passage from private living in one's own house to living in a constant communal atmosphere. If this transition is to be a happy one it needs to be handled delicately and with careful judgment as to the wishes of the old person.

\section{LONG TERM CARE OF THE DEMENTED}

If the old person is so demented that he is unable to grasp the implications of staying in his home or moving to residential accommodation, and on this subject has been declared legally incompetent, the actual decision rests with the legal guardian who must weigh the implications of the family's standpoint in relation to the patient's interests. Consideration must be given to the patient's real needs and how they would be answered by institutional care; the physical condition and personality of the patient; whether continued home management could or could not succeed, and the facilities available from the family and the community.

\section{ETHICAL BEHAVIOUR}

The tone of everyday conversation can contribute greatly to the happiness or to the unhappiness of an old person's life. A story from the Talmud illustrates this by the following aphorism:

A man may feed his father the choice parts of a turkey, and because of this shall deserve being consigned to the underworld after his death, and another may force his father to perform arduous work, and be rewarded with paradise in the world to come. ${ }^{7}$

In the first case, a wealthy son brings his father attractive and good food. The father asks his son from where he got the food, and receives the reply- "Never mind, your business is to eat and not to ask questions". In the second case, the son is a miller grinding flour by hand, and his father is presented with a command of obligatory service to the army, a situation fraught with great discomfort and danger. The son immediately offers to take his father's place, and the latter is left to take care of the grinding. The code of behaviour presented here is that of altruistic consideration. There is a lack of it plus a haughty lack of insight in the first case, and true altruistic consideration along with affectionate understanding in the second.

\section{DAY CENTRE INTERVENTION}

The management of chronic disability requires interventions with the purpose of improving bodily and mental function, and of raising the standard of day to day living. One of the modern facilities that can alleviate many of the problems of care giving is the day centre, particularly if the centre is devoted to the care of demented elderly. The advantage is the creation of a suitable social medium in which the demented person can feel a sense of belonging, and in which his limited ability to function will be seen and appreciated in the creativity of various types of occupational activity. ${ }^{8}$ In addition the centre shares the burden of care giving with the family, who gain some hours of respite during the day. Ethical dilemmas that may arise relate to the unwillingness of a demented person to accept any change in his daily routine; the imposition of activities not of his asking, and the necessity for the staff to control aberrant behaviour in an environment strange to him. The question is how does one act to obtain his assent (consent is often not an issue because of mental legal incompetence). Various steps can be taken to make the person feel that he is wanted, that he will be able to do something constructive, that this is a new job for him. These persuasive measures may aid the transition from an empty day at home doing nothing to a further period of creative socialising. The positive results of this kind of environmental treatment of demented patients in day centre settings are that they are given a feeling of purpose when they get up in the morning, and a sense of achievement in their daily living routine. ${ }^{9}$

\section{PARTICIPATION OF OLD PEOPLE IN MEDICAL RESEARCH}

Many of the advances in drug therapy, including medications that are designed to enhance cognitive function, have been based on double blind controlled trials. For these consent is usually obtained from the patients, of whom many will receive a placebo. The ethical dilemmas regarding participation of frail elderly people in clinical trials, and the question of informed consent for treatment, have exercised geriatric researchers for the past 15-20 years, as exemplified by the report of the Commission in the United States. ${ }^{10}$ The problem is twofold:

1) Much useful research has been carried out on old people-for instance, into the effect of age or disability on functional capacity, or into the response to physical exercise in old age. (See list of references in the editorial by Blair and Garcia.) ${ }^{11}$ There are still many areas of geriatric research, both physiological and therapeutic, which could usefully be investigated, but of course these require the patient to consent to participate. Frail old people in the community or in a nursing home may not completely understand the implications of a research protocol, and their vulnerability should be protected by an ethical code.

2) Clinical research on demented patients presents two opposing dilemmas: on the one hand the patient may be legally incompetent to judge whether he should consent or not; on the other hand, because of inappropriate assessment of patients' competency and/or their lack of awareness of the risks involved in the trial, it is possible that trials that could provide valuable practical scientific information, such as the use of medications in the treatment of dementia, might be cancelled. Research on patients declared legally incompetent must therefore show that the outcome is potentially of benefit to the given patient, and subject to the agreement of the legal guardian. The subject of correct assessment of competency has become of prime importance, and therefore guidelines for carrying out such assessments have been laid down by a multidisciplinary professional committee. ${ }^{12}$

One suggestion aimed at helping solving the first problem was to give the patients, following their having given oral consent, a trial of the treatment/research for a week, and then returning to assess how well the patients had understood it. After one week's experience, it was discovered that a significantly greater number than previously now understood the purpose and content of the research, its risks, and possible inconvenience: in fact $68 \%$ of the group signed a consent form. ${ }^{13}$ The limitations of this method were that it could not be tried with research involving invasive procedures or drugs with unknown side effects. ${ }^{14}$ 
The difficulty and disagreement among physicians about how to assess the capacity of old persons to consent, and regarding their competency has demanded the development of a clear methodology. Competence is not a unitary concept: there are multiple competencies, and the assessment must be fitted to the particular area in which competence is required. ${ }^{15}$ There may be disparity between cognitive capacity and competency. When research is conducted on Alzheimer's disease consideration must be given to the role of care giver and/or proxy, her decision making capacity and the factors governing it, and the impact of the research on her as well as on the patient. ${ }^{16}{ }^{17}$

\section{Cognitive assessment}

Standard cognitive assessment tests, such as the Folstein Mini-Mental State Examination (MMSE 1-30), ${ }^{18}$ Alzheimer's Disease Assessment Scale-cognition (ADAS-cog 1-76), ${ }^{19}$ and the Global Deterioration Scale, ${ }^{20}$ have proved useful in providing background semiquantification of cognitive status in relation to competency. Neuropsychological tests provide additional information on cognitive impairments, but may not be correlated with status of competency. Positive correlations were found for incompetence and marginal competence with patients' scores in MMSE $<17$ or ADAS $<33$, but scores indicating less cognitive disability were predictive of competency in only about two thirds of a group of 70 with Alzheimer's disease. ${ }^{21} 22$ For the legal standard for reasoning, word fluency was the best single predictor of competency but the MMSE, memory testing, and also verbal reasoning were not good multivariate predictors. ${ }^{23}$

\section{Competency capacity}

Competency capacity is based on understanding the risks and benefits of the research, its purpose, and being able to make the choice to agree or disagree to participate. This can be assessed by presenting one or two vignettes of a theoretical trial; by a theoretical consent form; by presenting an actual consent form relating to the specific research protocol, and through two semistructured interviews on the same topics 672 hours apart. The results of all of these methods should be compared with those from a group of care givers and a control group of healthy matched aged (Pucci, et al, ${ }^{21}$ pp 148-9).

A standard methodology for competency assessment is the MacArthur Competency Assessment Tool for Clinical Research (MacCat-CR). A hypothetical research protocol in standard language is read to the subject, followed by a structured interview about the protocol, in which are assessed the subject's ability of choosing, understanding, appreciation, and reasoning; the degree of cognitive impairment is reflected in the MMSE score. ${ }^{24-26}$ This tool has been used to distinguish between competency in general, and the capacity for decision making in the given research or treatment situation. Using this method, the performance of patients, their care givers and controls was compared, and it was shown that a certain proportion of Alzheimer's disease patients retained adequate capacity in their decision making and were therefore competent to consent to the research protocol. ${ }^{24-26}$

A further refinement in the definition of competency was proposed on the basis of legal principles, and accepted legal standards (LS), which demand the following evidence:

- LS1: the patient knows that he is faced with a choice;

- LS2: the patient has the capacity to make a reasonable choice comparable to that of a normal person;

- LS3: the patient is aware of the emotional consequences of his positive or negative choice;

- LS4: the patient is able to provide reasons for his choice;
- LS5: the patient has the capacity to understand the meaning of the information and the treatment situation.

Vignettes were presented to individual subjects and their controls, which mirrored a real life situation. Elderly potential candidates for a dementia trial showed a high degree of incompetence on LS5, and difficulties in LS3 and LS4 even in mild cases of dementia. ${ }^{27}$ At the level of LS4, these authors found that word fluency was the best single predictor of competency, but the MMSE, memory testing, or verbal reasoning were not good multivariate predictors. ${ }^{23}$

\section{Competency rating}

Competency rating: the rating of competency, based on the above protocols, can be done by an independent team of professionals with raters basing their decision on scores and free conversation during the interview, or by a coordinator blinded to the capacity scores (Kim, et al, ${ }^{25}$ pp 714-15). The classification of competent or incompetent subjects (with partial degrees of sufficiently and marginally competent) should be based also on comparison with controls. Care givers might serve as comparison subjects, but as they are also involved actively in decision making they themselves should be compared to controls matched for age. ${ }^{28}$ The methods of competence estimation must be validated in relation to capacity assessment, and both these measures structured in accordance with the specific topic of research (Kim, et al, 25 p 716).

The ethical problems pertaining to clinical research in the elderly cannot be solved by a single formula, because the question of competency and ability to understand the particular research topic must be considered in relation to its content and to the manner of presentation of the consent form. With the burgeoning of gerontological research, the methodology of capacity assessment is an ongoing subject that must be continually addressed.

\section{Authors' affiliations}

A J Rosin, Y van Dijk, Department of Geriatrics, Shaare Zedek Medical Center, Jerusalem, Israel

\section{REFERENCES}

1 Schultz WC. Joy: expanding human awareness. New York: Grove Press, 1967.

2 Parfit D. Personal identity. Philos Rev 1971;80:3-27.

3 Hughes JC. Views of the person with dementia. J Med Ethics 2001; 27:86-91.

4 Hope T. Aging research and families. J Med Ethics 1997;23:267-8.

5 Isaacs B, Livingstone $M$, Neville $Y$. The anatomy of neglect. In: Survival of the unfittest. London: Routledge \& Kegan Paul, 1972:34-49.

6 Code of Law-Yoreh Deah: ch 240. (In Hebrew)

7 Talmud Bavli Kiddushin: 31b.

8 Rosin AJ, Abramovitz L, Diamond J, et al. Environmental management of senile dementia. Soc Work Health Care 1985;11:33-43.

9 Berenbaum R, Bronner D, eds. Working with Alzheimer's patients: enrichment for those caring for the mentally impaired in the community. Jerusalem: Eshel and Melabev, 1996.

10 Lonergan ET, Krevans JR. A national agenda for research on aging. N Eng J Med 1991;324:1825-8.

11 Blair SN, Garcia ME. Get up and move: a call to action for older men and women [editorial]. J Am Geriatr Soc 1996:44:599-60.

12 Brodaty H, Dresser R, Eisner M, et al. Alzheimer's disease international working group for harmonisation of dementia drug guidelines for research involving human subjects with dementia. Alz Dis Assoc Disord 1999;13:71-9.

13 Rikkert MGMO, Bercken JHL, ten Have HAMJ, et al. Experienced consent in geriatrics research: a new method to optimise the capacity to consent in frail elderly subjects. J Med Ethics 1997;23:271-6.

14 Groudine S, Lumb BD. At the coalface-medical ethics in practice. First do no harm. J Med Ethics 1997;23:377-8.

15 Marson DC, Schmitt FA, Ingram KK, et al. Determining the competency of Alzheimer patients to consent to treatment and research. Alz Dis Assoc Disord 1994;8(suppl 4):5-18S

16 Karlawish J, Casarett D. Addressing the ethical challenges of clinical trials that involve patients with dementia. J Geriatr Psychiatry Neurol 2001;14:222-8. 
17 Kapp MB. Proxy decision making in Alzheimer disease research: durable powers of attorney, guardianship and other alternatives. Alz Dis Assoc Disord 1994;8(suppl 4):28-37S.

18 Folstein MF, Folstein SE, McHugh PR. "Mini-Mental State". J Psychiatr Res 1975; 12:189-98.

19 Mohs RC, Cohen L. Alzheimer's disease assessment scale. Psychopharmacol Bull 1988;24:627-8.

20 Reisberg B, Ferris SH, de Leon MJ, et al. The global deterioration scale for assessment of primary degenerative dementia. Am J Psychiatry 1982:139:1136-9

21 Pucci E, Belardinelli N, Borsetti G, et al. Information and competency for consent to pharmacological clinical trials in Alzheimer disease: an empirical analysis in patients and caregivers. Alz Dis Assoc Disord 2001;15:146-54.

22 Karlawish JH, Casarett D, Propert KJ, et al. Relationship between Alzheimer's disease severity and patient participation in decisions about their medical care. J Ger Psychiatr Neurol 2002;15:68-72.
23 Marson DC, Cody HA, Ingram KK, et al. Neuropsychological predictors of competency in Alzheimer's disease using a rational reasons legal standard. Arch Neurol 1995;52:955-9.

24 Applebaum PS, Grisso T. The MacArthur competence assessment toolclinical research. Sarasots, FL: Professional Resources Press, 2000.

25 Kim SYH, Caine ED, Currier GW, et al. Assessing the competence of persons with Alzheimer's disease in providing informed consent for participation in research. Am J Psychiatry 2001;158:714-15.

26 Applebaum PS, Grisso T, Frank E, et al. Competence of depressed patients for consent to research. Am J Psychiatry 1999;156:1380-4.

27 Marson DC, Ingram KK, Cody HA, et al. Assessing the competency of patients with Alzheimer's disease under different legal standards. Arch Neurol 1995;52:949-54.

28 Karlawish J, Casarett DJ, James BD. Alzheimer's disease patients' and caregivers' capacity, competency, and reasons to enrol in an early phase Alzheimer's disease clinical trial. J Am Geriatr Soc 2002;50:2019-24.

\section{Clinical Evidence - Call for contributors}

Clinical Evidence is a regularly updated evidence-based journal available worldwide both as a paper version and on the internet. Clinical Evidence needs to recruit a number of new contributors. Contributors are healthcare professionals or epidemiologists with experience in evidence-based medicine and the ability to write in a concise and structured way.

Areas for which we are currently seeking authors:

- Child health: nocturnal enuresis

- Eye disorders: bacterial conjunctivitis

- Male health: prostate cancer (metastatic)

- Women's health: pre-menstrual syndrome; pyelonephritis in non-pregnant women However, we are always looking for others, so do not let this list discourage you.

Being a contributor involves:

- Selecting from a validated, screened search (performed by in-house Information Specialists) epidemiologically sound studies for inclusion.

- Documenting your decisions about which studies to include on an inclusion and exclusion form, which we keep on file.

- Writing the text to a highly structured template (about 1500-3000 words), using evidence from the final studies chosen, within 8-10 weeks of receiving the literature search.

- Working with Clinical Evidence editors to ensure that the final text meets epidemiological and style standards.

- Updating the text every six months using any new, sound evidence that becomes available. The Clinical Evidence in-house team will conduct the searches for contributors; your task is simply to filter out high quality studies and incorporate them in the existing text.

- To expand the topic to include a new question about once every 12-18 months.

If you would like to become a contributor for Clinical Evidence or require more information about what this involves please send your contact details and a copy of your CV, clearly stating the clinical area you are interested in, to Klara Brunnhuber (kbrunnhuber@ bmigroup.com).

\section{Call for peer reviewers}

Clinical Evidence also needs to recruit a number of new peer reviewers specifically with an interest in the clinical areas stated above, and also others related to general practice. Peer reviewers are healthcare professionals or epidemiologists with experience in evidence-based medicine. As a peer reviewer you would be asked for your views on the clinical relevance, validity, and accessibility of specific topics within the journal, and their usefulness to the intended audience (international generalists and healthcare professionals, possibly with limited statistical knowledge). Topics are usually 1500-3000 words in length and we would ask you to review between 2-5 topics per year. The peer review process takes place throughout the year, and our turnaround time for each review is ideally 10-14 days.

If you are interested in becoming a peer reviewer for Clinical Evidence, please complete the peer review questionnaire at www. clinicalevidence.com or contact Klara Brunnhuber (kbrunnhuber@bmigroup.com). 